\title{
Partnering Strategies for Paired Formative Assessment in Programming
}

\section{Dr. Shanon Marie Reckinger, Stanford University}

Shanon Reckinger was a faculty in the department of Mechanical and Industrial Engineering at Montana State University from 2015-2017. Before her position at MSU, she was a Clare Boothe Luce Professor at Fairfield University in the department of Mechanical Engineering for four years. She received her $\mathrm{PhD}$ in Mechanical Engineering at the University of Colorado Boulder in August of 2011. Her research interests include ocean modeling, computational fluid dynamics, fluid dynamics, and numerical methods. Shanon has taught courses in thermodynamics, numerical methods (graduate), fluid dynamics, gas dynamics (graduate), computational fluid dynamics (undergrad/graduate), fundamentals of engineering, mathematical analysis in MATLAB. Currently, Shanon is enrolled in the Computer Science Education program at Stanford University.

\section{Dr. Bryce E. Hughes, Montana State University}

Bryce E. Hughes is an Assistant Professor in Adult and Higher Education at Montana State University, and holds a Ph.D. in Higher Education and Organizational Change from the University of California, Los Angeles, as well as an M.A. in Student Development Administration from Seattle University and a B.S. in General Engineering from Gonzaga University. His research interests include teaching and learning in engineering, STEM education policy, and diversity and equity in STEM. 


\title{
Partnering Strategies for Paired Formative Assessment in Programming
}

\begin{abstract}
In this paper, we present new partnering strategies to pair students for formative assessment in a programming course. These strategies, collaborative and cooperative learning, are two forms of active learning. Both forms have been widely tested in previous classroom experiments and show evidence of effectiveness. This study focused the application on how formative assessment (i.e. a weekly quiz) is administered, rather than on learning activities in general. A collaborative quiz is one based on the idea of paired programming, a technique that has become well-received in computer science. This type of quiz requires the pair of students to program together, using one computer to turn in one final solution. The second method, a cooperative quiz, allows students to collaborate as much or as little as they prefer. For a cooperative quiz, students must each use their own computer to write and submit their own solution, but any collaboration with their partner is allowed. To account for student preferences for active or independent learning, these strategies were also guided by how students are paired. To do this, the Felder-Silverman learning style inventory was used to categorize students along the model's active-reflective dimension as reflective, active, or "in-between" (neutral) learners. Students were partnered throughout the semester with a variety of partners with attention to mixing and matching their preferred learning styles to determine any effects of partnering.
\end{abstract}

This study took place across three sections of a sophomore-level programming class in a midsize, public university in the western United States. The sample included approximately 100 primarily second-year mechanical engineering undergraduate students. The course is a required programming course using MATLAB. A weekly quiz was administered across each of the sections differently. This was done to test the relationship between strategy and assessment performance. Therefore, each week there was a section of students taking a collaborative, cooperative, and independent quiz. All sections were given the opportunity to take the same total number of each quiz type and all sections were taught by the same instructor. A standardized rubric was used to score student performance and compare across sections, across quiz styles, and across learning styles.

The research question guiding this paper is: how does the quiz style and/or partner learning style preference affect student performance on formative assessment? Both quantitative and qualitative methods were used to address this question. Statistical analysis was used to determine the average differences in quiz performance based on quiz style, mixed or matched learning style partnering, and the combination of the above. Several quiz sessions were videotaped, and this data was used to discern the interpersonal dynamics of different partnering conditions. This paper will focus on those results. The results from the statistical analysis demonstrates that working with a partner improved student performance over individual assessment. Video observations confirmed the statistical results, and provide more detail regarding the interpersonal dynamics of each type of student pairing. Additionally, we will present student narrative feedback.

\section{Introduction}


The study presented here aims to present partnering strategies in pair programming for in-class formative assessment. Formative assessment is a useful tool for keep students on track and on schedule with their learning (Cooper, Robinson, \& Patall, 2006; Ramdass \& Zimmerman, 2011). However, formative assessment in the form of in-class quizzes can often create a stressful environment because of testing anxiety. This work not only looked at whether implementing partner quizzes can mitigate this anxiety, but also compared partnering strategies to create the most effective partnerships.

\section{Background}

This work is grounded in an active learning framework. The partnering strategies were designed based on the concepts of cooperative and collaborative learning (Bruffee, 1995), which are two strategies for organizing students in the classroom. Both cooperative and collaborative learning fall under the umbrella of active learning (Prince, 2004). Cooperative learning involves students forming groups to solve problems but are individually assessed (Feden \& Vogel, 2003; Johnson, Johnson, \& Smith, 1998). The primary motivation of cooperative learning is to combat the competitive nature of most classrooms (Johnson \& Johnson, 1989). Collaborative learning also involves students forming groups to solve problems, but tends to emphasize group dynamics rather than individual assessment (B. L. Smith \& MacGregor, 1992). The primary motivation of collaborative learning is teamwork, rather than individual excellence. An advantage to incorporating teamwork into formative assessment is that it prepares students for varies skills outlined in the ABET student outcomes.

Both collaborative and cooperative learning have been widely tested in various classroom experiments and show evidence of effectiveness (Coccoli, Stanganelli, \& Maresca, 2011; Freeman et al., 2014; Sein-Echaluce, Fidalgo-Blanco, \& García-Peñalvo, 2016; K. A. Smith, Douglas, \& Cox, 2009; Stump, Hilpert, Husman, Chung, \& Kim, 2011). A collection of review articles on collaborative learning collectively looked at over 200 studies (Johnson \& Johnson, 1989; Johnson et al., 1998; Springer, Stanne, \& Donovan, 1999). They found that collaborative learning (compared to individual learning) improved academic achievement, quality of interpersonal interactions, self-esteem, perceptions of social support, student attitudes, liking among students, and retention in academic programs. Prince (2004) nicely summarized the effect sizes of collaborative learning on each of the aforementioned learning outcomes. Another important factor to consider when incorporating collaborative learning is frequency. Analysis by Springer et al. (1999) showed that a medium amount of group work (compared to a small amount or a large amount) produced the highest effect size on student achievement. Cooperative learning outcomes were also reviewed in Johnson and Johnson (1989) and Johnson et al. (1998). They found that cooperative learning (compared to competitive learning) improved academic achievement, interpersonal relationship, liking among students, perceptions of social support, and self-esteem. Research does show that cooperative and collaborative learning are more beneficial than independent learning, but no study has assessed the difference between these two conditions, especially in their effect on learning computer programming.

This work uses the Felder-Soloman learning style model to classify students based on their preference for active or reflective learning (Felder \& Brent, 2005; Felder \& Silverman, 1988; 
Richard M Felder \& Barbara A Soloman, n.d.). This model was developed within engineering education and has been validated and widely used within the field (Hawk \& Shah, 2007; Litzinger, Lee, \& Wise, 2005; Litzinger, Lee, Wise, \& Felder, 2007; Van Zwanenberg, Wilkinson, \& Anderson, 2000; Zywno, 2003). Learning style preferences are categorized along four distinct dimensions: perception (sensing versus intuitive), input (visual versus verbal), processing (active versus reflective), and understanding (sequential versus global). This study focused on the processing dimension as a heuristic to guide the construction of formative assessments to provide active and reflective conditions that reflected cooperative, collaborative, and independent learning. Active learners tend to prefer learning styles that allow them to discuss, apply, try, and experiment. They tend to prefer working with others. Reflective learners tend to prefer learning styles that allow them to think quietly and analyze deeply, before trying anything out. They tend to prefer working individually. The R.M. Felder and B.A. Soloman (n.d.) Index of Learning Styles (ILS) instrument was also chosen because it is web-based and convenient for the students to use.

\section{Sample Description}

This study takes place in a mid-size, public university in the western United States. The sample for this study includes approximately 93 mechanical engineering undergraduate students across three sections of a required programming course in MATLAB, taught by the same instructor. Students were first provided the Felder-Soloman learning styles inventory in order to categorize themselves as active, reflective, or neutral learners. The scale scores range from -11 to 11 , with scores less than -5 representing reflective learners, and scores greater than 5 representing active learners. Those with strong preferences toward active or reflective (scores with an absolute value of 5 or higher) were categorized as such; those toward the middle were classified as neutral in their preference. Over the course of the semester students were then provided the opportunity to take weekly quizzes in three formats designed to provide collaborative, cooperative, and individual learning. For the partnered conditions (collaborative and cooperative), students were partnered with different peers over the course of the semester to vary the learning style preferences of their partners. To the extent possible, students were partnered with peers who perform academically similar to try to mitigate the confounding effect of working with a higher performing partner.

Collaborative, cooperative, and independent quiz conditions map onto the Felder-Soloman processing dimension. A collaborative quiz is the most active type. For this type of quiz, partners were required to use only a single computer. They write one code file and submit one file for grading. In this format, one student is typically the "driver" (the one who types) while the other student is "navigator" (observes the work of the driver, providing suggestions, and finding defects). This concept is based on pair programming used in computer science. Pair programming has been shown to improve code writing, confidence, and enjoyment of computer programming, among many other benefits (McDowell, Werner, Bullock, \& Fernald, 2003). Other studies have shown that pair programming produces higher quality code in half the time (Cockburn \& Williams, 2000; Williams, Kessler, Cunningham, \& Jeffries, 2000). Most studies show that student performance on exams is the same and in some cases may be better for students who did pair programming on assignments versus those who completed assignments individually (McDowell, Werner, Bullock, \& Fernald, 2002; Nagappan et al., 2003). 
A cooperative quiz is slightly less active than the collaborative version. For this type of quiz, partners are both writing their own codes on their own computers. Each partner submits their own code for grading. They are allowed to collaborate as much or as little as they would like with their assigned partner, though they are not allowed to work with any other student. This type of quiz reduces the competitive nature of the environment, as students are able and encouraged to help each other progress through the quiz. However, students working on a cooperative quiz are able to work completely independent of each other; hence the assessment that a cooperative quiz is less "active" than a collaborative quiz.

\section{Methods}

Data was collected through a variety of methods. First, students were surveyed at the end of the semester and asked to reflect on the partnerships. Each student was partnered throughout the semester with three different partners. They were given the opportunity to work with each of the three partners in both collaborative and cooperative quiz environments. The survey asked them to rate the partnership and provide comments on effectiveness, especially if they found working with a partner stressful. Students were also asked what type of quiz they preferred (individual, collaborative, or cooperative). Finally, some partnerships were video recorded during the quiz in order to have video data of the quiz experience for different types of partnerships. Summary descriptive statistics of student experiences with partnering, and description of the video observations are presented in this paper. Further statistical analysis of the relationships among quiz style, learning preference, partnering, and academic performance using a three-level hierarchical linear growth model is presented in a separate manuscript (Reckinger, Manuscript in preparation); the focus of this practice paper is provide a more holistic discussion of observations in the classroom and provide narrative feedback from students. The most interesting and relevant results from this data is summarized in the following section.

\section{Results and Discussion}

\section{Student Feedback on Partnering}

Students generally preferred the partner quizzes over individual quizzes. This data is presented in previous work (Reckinger, Manuscript in preparation). Table 2 and Table 1 summarize students' negative and positive comments, respectively. These comments presented are chosen as representative of the comments received. These comments indicate that many students found partnering helpful for their learning, and helped reduce stress levels during the quiz time. This is true for reflective, neutral, and active learners. This is also true for students performing well and less well in the course. There were many good points raised that demonstrate some negative aspects of partner quizzes. These include the challenges when your partner is not "good", the extra time required for discussion, and feeling you are not contributing enough to the partnership. However, the comments indicate that it important for partners to feel equal, so partnering students by GPA or course grade seems like a good approach to achieve this. For best understanding of the overall student responses, it is recommended that the reader reads through the table of comments. Comments also indicated that for most students, having a partner reduced their stress level. 


\section{Positive Comments}

"All my partners were great. XXX and YYY helped me a lot during the labs." -Active Learner (Grade: $93.3 \%$, Ratings: $5 / 5 / 5$ )

"Really enjoyed the partner quizzes. They helped a lot when I was struggling." -Neutral Learner (Grade: $92.7 \%$, Ratings: 5/5/5)

"Stress levels were halved with a partner quiz and I certainly feel I learned more effectively this way." -Neutral Learner (Grate: $81.5 \%$, Ratings: 4/4/3)

"Partners were badass." -Neutral Learner (Grade: 84.0, Ratings: 4/4/5)

"XXX and I got along and I felt that I learned more from him and explaining some things from him." -Neutral Learner (Grade: $80.5 \%$, Ratings: $5 / 5 / 4$ )

"I liked the partner quizzes with a single file. They allowed for complete collaboration." Neutral Learner (Grade: 93.6\%, Ratings: 4.5/5/5)

(A comment on final partnership) "We thought similarly and were both fairly patient with each other. It also helped that we were more used to the partner quizzes at this point." -Neutral Learner (Grade: $92.3 \%$, Ratings: $3 / 2 / 5$ )

"(A comment on one partnership) "We had the same skill level and built off of each other, but our skill level was low." -Reflective Learner (Grade: 76.0, Ratings: 4/2/3)

"XXX and I often were on the same wavelength during quizzes. We seemed to get along together and were able to communicate openly." -Active Learner (Grade: 84.1, Ratings: $5 / 2 / 5)$

(A comment on one partnership) "Often would catch mistakes that I would make. Also made sure I knew the material." -Neutral Learner (Grade: 95.8, Ratings: 2/4/3)

"The partner quizzes definitely felt less frustrating than those done solo." -Active Learner (Grade: 92.3\%, Ratings: ?/4/2)

"I felt more confident when working with a partner." -Neutral Learner (Grade: 89.8\%, Ratings: 5/4/4)

"I had great partners all semester"-Neutral Learner (Grade: 91.6\%, Ratings: 4/4/5)

"I liked the partner quizzes and how you switched us up." -Neutral Learner (Grade: 85.8\%, Ratings: $1 / 2 / 5)$

(A comment on one partnership) "He didn't know how to do anything, but it made me learn by teaching." -Neutral Learner (Grade: $81.6 \%$, Ratings: $3 / 3 / 3$ )

"Regardless of the partners, I still though partner quizzes were very effective in reducing stress and overall performance on quizzes." -Active Learner (Grade: $84.9 \%$, Ratings: 3/2/3)

"XXX and YYY were both MATLAB wizards so I learned a lot from them. ZZZ and I were mutually lost so our combined desperation led to results." - Neutral Learner (Grade: 85.0\%, Ratings: $5 / 5 / 5$ )

"I felt well matched with (partners) 1 and 3 but XXX had skills way above my head so I didn't contribute as much as I could have." -Neutral Learner (Grate: 83.3\%, Ratings: 5/4/5)

"The partner quizzes were awesome because you can have immediate feedback if you are stuck on something." -Neutral Learner (Grade: 69.1\%, Ratings: 5/5/5)

"Having any of the partners was not super stressful, about the only big benefit was being able to lighten the work." -Reflective Learner (Grade: 76.4, Ratings: 3/4/3.5)

"Having a partner helps with catching syntax errors, and can make it easier to work quickly when you have a similar skill level." -Neutral Learner (Grade: $82.2 \%$, Ratings: 3/4/4)

Table 1 - Summary of students' positive comments in regards to partnering. The numbers in parenthesis are their final course grade, followed by how the student rated their three partners on a scale of 1-5 (1-bad partner, 5-good partner). 


\begin{tabular}{|l|}
\hline Negative Comments \\
\hline "Partner quizzes generally blew. It really depended on if you got a great partner or not." - \\
Reflective Learner (Grade: $90.1 \%$, Ratings: $1 / 1 / 5)$ \\
\hline "I don't like partners"-Neutral Learner (Grade: $83.3 \%$, Ratings: $4 / 2 / 4)$ \\
\hline "Partner quizzes were only helpful when you and your partner both had a good idea of what \\
was going on." -Active Learner (Grade: $81.3 \%$, Ratings: $4 / 5 / 2$ ) \\
"The “one m-file" quizzes generally felt to me like single quizzes with someone breaking my \\
concentration." -Reflective Learner (Grade: $90.8 \%$, Ratings: $4 / 3 / 2$ ) \\
\hline (A comment on one partnership) "worked well together but I felt guilty because he obviously \\
knew more"-Reflective Learner (Grade: $87.5 \%$, Ratings: $3 / 4 / 5$ ) \\
\hline "It was annoying trying to help your partner through the quiz when you are trying to get the \\
quiz done and they are behind asking for help." -Neutral Learner (Grade: $84.5 \%$, Ratings: \\
2/3/1) \\
\hline (A comment one on partnership) "He was very knowledgeable on the subject, moreso than I. I \\
felt I wasn't as much of a help to him as he was to me." -Neutral Learner (Grade: $70.6 \%$, \\
Ratings: $5 / 3 / 5$ ) \\
\hline "If I know a topic really well or even just alright, partner quizzes slowed me down or \\
distracted me. This is why I preferred submit own m-file." -Neutral Learner (Grade: $88.1 \%$, \\
Ratings: $4 / 3 / 1$ ) \\
\hline (A comment on one partnership) "We did not work very well because he wasn't open to trying \\
different methods on the quiz." -Active Learner (Grade: 87.1 , Ratings: $2 / 3 / 3$ ) \\
\hline "It is hard with the time restriction to get everything done because you discuss everything." - \\
Active Learner (Grade: $85.0 \%$, Ratings: $5 / 5 / 3$ ) \\
\hline
\end{tabular}

Table 2 - Summary of students' negative comments in regards to partnering. The numbers in parenthesis are their final course grade, followed by how the student rated their three partners on a scale of 1-5 (1-bad partner, 5-good partner).

Finally, there was an interesting demographic difference in feedback on the partnerships that is included in Table 3. Female students reported a less positive experience with partnerships than male students. Female students were more likely to prefer individual quizzes and more likely to rate their partners lower. One is cautioned from generalizing these findings at this stage given the small number of women in the sample (7/93), but these findings lead to an interesting question for future research regarding women engineering students' experiences with group work. Given the small number of women in mechanical engineering, group work experiences may exacerbate existing feelings of isolation or being "singled out" as the only woman, or one of a few women, in the classroom (Heyman, Martyna, \& Bhatia, 2002).

\section{Gender Preferences}

When students were asked what type of partnerships they preferred, $26.1 \%$ of female students preferred taking individual quizzes, where $11.6 \%$ of male students preferred taking individual quizzes.

When asked to rate their partners, $21.7 \%$ of female students rated their partners as bad, where $5.3 \%$ of male students rated their partners as bad.

Table 3 - Differences in preferences by gender.

\section{Video Observations on Partnering}


Table 4 and Table 5 summarize the observations from the video data collected for collaborative and cooperative partnerships, respectively. These observations indicate that partnerships may be most successful when mixing reflective and active learners, congruent with our statistical analysis (Reckinger, Manuscript in preparation). The authors encourage faculty to present to students the types of roles partners can assume (e.g., drivers and navigators) so students can choose the roles they prefer, rather than organically assuming these roles. If students make a conscious choice and discuss with their partner in advance, it should lead to more clear roles.

\section{Collaborative Partnering Observations}

In most cases recorded (5 out of 6 ) where partnership included one active and one reflective learner, the active learner was the navigator and the reflective learner was a driver. This was self-selected, not instructed. The one case where the active learner was driving, the partnership was obviously less productive and fluid. The active driver kept the mouse and keyboard available for the navigator to jump in (which never happened). And it appeared that neither person had a clear role. The active driver did very little typing, almost not sure what to do. In the rest of the cases with a reflective driver, that role was clear and that person was typing actively the entire time.

\section{Two types of drivers:}

1. Thinking out loud drivers- these types of students appeared to verbalize their thoughts while working through the code. This allowed their partners to somewhat seamlessly interact with these thoughts, meaning that the driver and navigator truly worked as one. In these cases, the driver was posing questions, even somewhat rhetorically, as one might do while thinking. The speech is often quiet, focused, concise, and calm.

2. Internally thinking drivers - these types of students appeared to be internally thinking deeply while working through the code, but not speaking much. In most cases, they only spoke when asked a question. They were generally internally consumed. This type of driver appeared to be less effective than the first type.

\section{Two types of navigators:}

1. Vocal navigators - in these cases, the navigator would either speak a lot, almost the whole time, even with no verbal response by the driver. These navigators would read the specs out loud, would read the code out loud, and would speak their thoughts out loud. Some drivers indicate this was distracting or stressful, while other drivers made no mention of it at all.

2. Reading navigators - in these cases, the navigator spoke very little. These navigators spent a lot of time reading the specs and guiding the driver to meet them with only short, brief comments/corrections. They also spent a lot of time silently reading the code and watching the code being built, and would rather patiently give input and guide the driver.

\section{Observations of active partners (typically navigators):}

- Pen spinning

- Chair swiveling

- Knee shaking

- Pointing and hand motions

- Writing

Table 4 - Observations from video data on collaborative quizzes. 


\section{Corporative Partnering Observations}

“Parallel Programming" - this occurred most frequently/obviously when two reflective learners where partnered, but happened with many other partnerships, as well. They would program their own codes with very little verbal discussion, but check in regularly by looking at each other's screen, reminiscent of "parallel play" in early childhood development. There appeared to be a natural flow to the experience, in addition to a sense of partnership with almost no explicit evidence of interaction. This partnership is not equivalent to "individual programming", as there is an enormous amount of non-verbal interaction and collaboration.

"Dual Programming" - this occurred most frequently with two active learner partners, when partners were more outgoing and social, or when partners were friends. In these cases, the students would build two codes, more or less, together. It is most similar to the collaborative partnership, except that partners had to build two codes. In these cases, both partners would make sure each person's code was progressing as they solved the problem. If either person's code was not working, they would debug it together and move forward.

"Individual Programming" - this occurred most frequently, in general. This was most typical in partnerships where both students, or either student, was performing average or below average in the course overall. Students would work, more or less, individually. The majority of the period was silent and most of the time students were only looking at and interacting with their own screens. Throughout the session, students may ask their partner a question or look at their partners screen. However, discussion was minimal.

Table 5 - Observations from video data on cooperative quizzes.

\section{Conclusions}

This paper provides holistic data on the experiences of partnering in formative assessment in a programming course. It provides other faculty teaching programming courses and experimenting with pair programming some data to base their own approaches on. In general, the authors believe that partnering can provide benefits to the students learning experience and reduce stress levels. Student comments indicated it was important that they were partnered with someone a similar skill level with them (on both ends) so that they feel they are contributing and also not pulling all the weight. Observations of the video data indicated that partnerships fell into different categories. It is recommended that faculty discuss these types of roles prior to students partnering so that students can explicitly decide what types of partnerships they would like to have.

\section{Acknowledgements}

We would like to thank the seven undergraduate teaching assistants who helped run this semester's course: Daniel Moore, Seth Whiteside, Lincoln DiLorenzo, Jaclyn Wing, Connor Klein, Quinton Holmlund, and Tanner Tofthagen. We would like to acknowledge their enormous efforts in this study including proctoring and grading all the quizzes. We would also like to thank the TAs for all the data entry and record keeping that allowed us to analyze this work on so many dimensions. Secondly, we would like to thank the 96 EMEC 203 students who gave their time and effort to this class. They went above and beyond to provide additional feedback through the many surveys, outside of the class requirements. Lastly, we would like to 
thank Montana State University and the department of Mechanical and Industrial Engineering for providing the resources needed to complete this study.

\section{References}

Bruffee, K. A. (1995). Sharing our toys: Cooperative learning versus collaborative learning. Change: The Magazine of Higher Learning, 27(1), 12-18.

Coccoli, M., Stanganelli, L., \& Maresca, P. (2011). Computer supported collaborative learning in software engineering. Paper presented at the Global Engineering Education Conference (EDUCON), 2011 IEEE.

Cockburn, A., \& Williams, L. (2000). The costs and benefits of pair programming. Extreme programming examined, 223-247.

Cooper, H., Robinson, J. C., \& Patall, E. A. (2006). Does homework improve academic achievement? A synthesis of research, 1987-2003. Review of educational research, $76(1), 1-62$.

Feden, P. D., \& Vogel, R. M. (2003). Methods of teaching: Applying cognitive science to promote student learning: McGraw-Hill Humanities, Social Sciences \& World Languages.

Felder, R. M., \& Brent, R. (2005). Understanding student differences. Journal of engineering education, 94(1), 57-72.

Felder, R. M., \& Silverman, L. K. (1988). Learning and teaching styles in engineering education. Engineering education, 78(7), 674-681.

Felder, R. M., \& Soloman, B. A. (n.d.). Index of Learning Styles. Retrieved from http://www.ncsu.edu/felder-public/ILSpage.html.

Felder, R. M., \& Soloman, B. A. (n.d.). Learning styles and strategies. Retrieved from http://www.ncsu.edu/felder-public/ILSdir/styles.pdf.

Freeman, S., Eddy, S. L., McDonough, M., Smith, M. K., Okoroafor, N., Jordt, H., \& Wenderoth, M. P. (2014). Active learning increases student performance in science, engineering, and mathematics. Proceedings of the National Academy of Sciences, $111(23), 8410-8415$.

Hawk, T. F., \& Shah, A. J. (2007). Using learning style instruments to enhance student learning. Decision Sciences Journal of Innovative Education, 5(1), 1-19.

Heyman, G. D., Martyna, B., \& Bhatia, S. (2002). Gender and achievement-related Beliefs among engineering students. Journal of Women and Minorities in Science and Engineering, 8(1), 41-52.

Johnson, D. W., \& Johnson, R. T. (1989). Cooperation and competition: Theory and research: Interaction Book Company.

Johnson, D. W., Johnson, R. T., \& Smith, K. A. (1998). Active learning: Cooperation in the college classroom: ERIC.

Litzinger, T. A., Lee, S. H., \& Wise, J. C. (2005). A study of the reliability and validity of the Felder-Soloman Index of Learning Styles. Paper presented at the Proceedings of the 2005 American Society for Education Annual Conference \& Exposition.

Litzinger, T. A., Lee, S. H., Wise, J. C., \& Felder, R. M. (2007). A psychometric study of the index of learning styles C. Journal of engineering education, 96(4), 309. 
McDowell, C., Werner, L., Bullock, H., \& Fernald, J. (2002). The effects of pair-programming on performance in an introductory programming course. ACM SIGCSE Bulletin, 34(1), $38-42$.

McDowell, C., Werner, L., Bullock, H. E., \& Fernald, J. (2003). The impact of pair programming on student performance, perception and persistence. Paper presented at the Proceedings of the 25th international conference on Software engineering.

Nagappan, N., Williams, L., Ferzli, M., Wiebe, E., Yang, K., Miller, C., \& Balik, S. (2003). Improving the CS1 experience with pair programming. ACM SIGCSE Bulletin, 35(1), 359-362.

Prince, M. (2004). Does active learning work? A review of the research. Journal of engineering education, 93(3), 223-231.

Ramdass, D., \& Zimmerman, B. J. (2011). Developing self-regulation skills: The important role of homework. Journal of advanced academics, 22(2), 194-218.

Reckinger, S. M., B. Hughes. (Manuscript in preparation). Partnering Strategies for Timed Pair Programming: A Multi-Level Model. Advances in Engineering Education.

Sein-Echaluce, M. L., Fidalgo-Blanco, Á., \& García-Peñalvo, F. J. (2016). Students’ knowledge sharing to improve learning in engineering academic courses.

Smith, B. L., \& MacGregor, J. T. (1992). What is collaborative learning: Washington.

Smith, K. A., Douglas, T. C., \& Cox, M. F. (2009). Supportive teaching and learning strategies in STEM education. New Directions for Teaching and Learning, 2009(117), 19-32.

Springer, L., Stanne, M. E., \& Donovan, S. S. (1999). Effects of small-group learning on undergraduates in science, mathematics, engineering, and technology: A meta-analysis. Review of educational research, 69(1), 21-51.

Stump, G. S., Hilpert, J. C., Husman, J., Chung, W. t., \& Kim, W. (2011). Collaborative learning in engineering students: Gender and achievement. Journal of engineering education, 100(3), 475-497.

Van Zwanenberg, N., Wilkinson, L., \& Anderson, A. (2000). Felder and Silverman's Index of Learning Styles and Honey and Mumford's Learning Styles Questionnaire: how do they compare and do they predict academic performance? Educational Psychology, 20(3), 365-380.

Williams, L., Kessler, R. R., Cunningham, W., \& Jeffries, R. (2000). Strengthening the case for pair programming. IEEE software, 17(4), 19-25.

Zywno, M. S. (2003). A contribution to validation of score meaning for Felder-Soloman's index of learning styles. Paper presented at the Proceedings of the 2003 American Society for Engineering Education annual conference \& exposition. 